\title{
Van der Waals Integrated Silicon/Graphene/AlGaN Based Vertical Heterostructured Hot Electron Light Emitting Diodes
}

\author{
Nallappagari Krishnamurthy Manjunath ${ }^{1,2}$, Chang Liu ${ }^{1,2}$, Yanghua Lu ${ }^{1,2}$, Xutao $\mathrm{Yu}^{1,2}$ \\ and Shisheng Lin $1,2,3, *$ \\ 1 College of Microelectronics, Zhejiang University, Hangzhou 310027, China; manjunath@zju.edu.cn (N.K.M.); \\ 12031105@zju.edu.cn (C.L.); luyanghua6@zju.edu.cn (Y.L.); 21931041@zju.edu.cn (X.Y.) \\ 2 College of Information Science and Electronic Engineering, Zhejiang University, Hangzhou 310027, China \\ 3 State Key Laboratory of Modern Optical Instrumentation, Zhejiang University, Hangzhou 310027, China \\ * Correspondence: shishenglin@zju.edu.cn; Tel.: +86-0571-87951555
}

Received: 14 November 2020; Accepted: 11 December 2020; Published: 21 December 2020

\begin{abstract}
Silicon-based light emitting diodes (LED) are indispensable elements for the rapidly growing field of silicon compatible photonic integration platforms. In the present study, graphene has been utilized as an interfacial layer to realize a unique illumination mechanism for the silicon-based LEDs. We designed a Si/thick dielectric layer/graphene/AlGaN heterostructured LED via the van der Waals integration method. In forward bias, the Si/thick dielectric $\left(\mathrm{HfO}_{2}-50 \mathrm{~nm}\right.$ or $\left.\mathrm{SiO}_{2}-90 \mathrm{~nm}\right)$ heterostructure accumulates numerous hot electrons at the interface. At sufficient operational voltages, the hot electrons from the interface of the Si/dielectric can cross the thick dielectric barrier via the electron-impact ionization mechanism, which results in the emission of more electrons that can be injected into graphene. The injected hot electrons in graphene can ignite the multiplication exciton effect, and the created electrons can transfer into p-type $\mathrm{AlGaN}$ and recombine with holes resulting a broadband yellow-color electroluminescence (EL) with a center peak at $580 \mathrm{~nm}$. In comparison, the n-Si/thick dielectric/p-AlGaN LED without graphene result in a negligible blue color EL at $430 \mathrm{~nm}$ in forward bias. This work demonstrates the key role of graphene as a hot electron active layer that enables the intense EL from silicon-based compound semiconductor LEDs. Such a simple LED structure may find applications in silicon compatible electronics and optoelectronics.
\end{abstract}

Keywords: van der Waals contact; graphene; hetero-structure; light emitting diode

\section{Introduction}

Light-emitting diodes (LEDs) are widely adopted electrically generated light emitting sources and possess vital applications in modern society, specifically III-V based compound semiconductors (GaN, AlGaN, etc.), which are the most commercialized materials for the realization of efficient LEDs [1-4]. However, the quest for silicon compatible LEDs has huge commercial importance for their applications in monolithic optoelectronic devices and integrated photonic platforms [5-7]. To date, effectually competent silicon-based LEDs have not been realized, mainly due to (i) the indirect bandgap of silicon ( $\mathrm{Si}$ ), (ii) issues with the electron mobility of silicon, (iii) comparatively low probability of productive recombination transition in Si quantum cages (Si nanostructures), and (iv) the limited scope of light emission from the seeded Si by foreign light active ingredients [8,9]. In the present work, we have demonstrated the possibility of high intense LEDs by combining $\mathrm{Si}$, double-layer graphene (DLG), and p-type AlGaN [10-12].

In recent years, graphene, a two-dimensional (2d) material, has gained huge attention because of its novel superior electronic behavior and has been extensively studied as a highly conductive 
and transparent electrode for LEDs, and a suitable choice over Indium Tin Oxide (ITO) [13-17]. The double-layer graphene (DLG) is considered to be a better candidate over the monolayer as a substrate and a conductive electrode in device fabrication because DLG possesses better mechanical properties, which can avoid the misconceptions caused by damage or discontinuity in monolayer graphene [18]. Herein, we have presumed DLG as an interfacial layer in between the Si/dielectric layer and p-AlGaN layer to realize a unique illumination mechanism for better performance of LEDs. Recently, the twisted double-layer graphene (DLG) has been demonstrated to be superconducting at low temperatures [19]. Furthermore, as graphene has a zero band gap, the hot electron can experience multi electron-electron interaction before cooling in the time scale of several tens or hundreds of $\mathrm{fs}$, which results in the effect of carriers multiplication (CM) been proven by many reports [20,21].

For Si and III-V compound semiconductors, a well-defined epitaxial growth of multiple quantum wells or heterostructure is needed to achieve efficient LEDs, and fabrication of such delicate heterostructures require molecular beam epitaxy $(\mathrm{MBE})$ or metal-organic chemical vapor deposition (MOCVD) exclusively [22-24]. The van der Waals integration method [25,26] is a simple and fast method to achieve material integration. It allows for device design flexibility because it involves the direct physical assembly of pre-building blocks of the device. We have followed the van der Waals integration method to realize the silicon-based compound semiconductor heterostructured LEDs: (i) $\mathrm{n}-\mathrm{Si} / \mathrm{HfO}_{2}(50 \mathrm{~nm}) / \mathrm{DLG} / \mathrm{p}-\mathrm{AlGaN} \mathrm{LED}$, (ii) n-Si/SiO $2(90 \mathrm{~nm}) / \mathrm{DLG} / \mathrm{p}-\mathrm{AlGaN}$ LED, (iii) graphene free n-Si/HfO $\mathrm{Hf}_{2}(50 \mathrm{~nm}) / \mathrm{p}-\mathrm{AlGaN}$ LED, (iv) graphene free $\mathrm{n}-\mathrm{Si} / \mathrm{SiO}_{2}(90 \mathrm{~nm}) / \mathrm{p}-\mathrm{AlGaN} \mathrm{LED}$, and (v) graphene free $\mathrm{n}-\mathrm{Si} / \mathrm{Al}_{2} \mathrm{O}_{3}(10 \mathrm{~nm}) / \mathrm{p}-\mathrm{AlGaN}$ LED. We carried out a comprehensive EL study of these LEDs and emphasized the key role of DLG for the illumination mechanism of LED at forward bias voltages. The van der Waals integrated silicon-based LED with graphene as an interfacial layer may have considerable applications in the field of silicon compatible integrated optoelectronics.

\section{Materials and Methods}

The fabrication of the $\mathrm{n}-\mathrm{Si} / \mathrm{HfO}_{2} / \mathrm{DLG} / \mathrm{p}-\mathrm{AlGaN}$ LED was done using the van der Waals integration method. The $\mathrm{n}-\mathrm{Si} / \mathrm{HfO}_{2}(50 \mathrm{~nm})$ heterostructure was physically attached to the DLG/p-AlGaN heterostructure. This physically attached combination was clamped tightly, resulting in the completion of the fabrication of the LED. The device area is typically $0.5 \mathrm{~cm} \times 0.5 \mathrm{~cm}$. The fabrication of other LEDs was also accomplished similarly as above-mentioned. The p-AlGaN layer with a thickness of $800 \mathrm{~nm}$ was grown on a pre-designed AIN/Sapphire substrate via MOCVD (Supplementary Materials). Graphene was prepared on the $\mathrm{Cu}$ foils using the chemical vapor deposition (CVD) method and the temperature profile of the CVD growth of polycrystalline graphene is shown in Figure S1. DLG was transferred onto the surface of the $\mathrm{p}-\mathrm{AlGaN}$ by following the PMMA assisted layer-by-layer graphene transfer method (detailed in the Supplementary Materials). The $\mathrm{Au} / \mathrm{Cr}$ and $\mathrm{Au} / \mathrm{Ni}$ electrodes were achieved on the edge of the $\mathrm{n}-\mathrm{Si}$ and $\mathrm{p}-\mathrm{AlGaN}$, respectively, via the electron beam evaporation technique and followed by annealing at $600{ }^{\circ} \mathrm{C}$ under an inert atmosphere for better electrical contacts (Supplementary Materials).

Cross-sectional samples of the n-Si/ $/ \mathrm{HfO}_{2}$ heterostructure was obtained using a Dual-beam FIB (Quanta 3D FEG, FEI), which were further characterized via high-resolution Transmission Electron Microscope (TEM) images and scanning TEM-x-ray energy dispersive spectra (STEM-EDX) mapping inside a TEM (FEI-TITAN operating at $200 \mathrm{kV}$ ). Raman spectra on graphene was collected using a Renishaw Micro Raman Instrument (Figure S2), with a laser source of $532 \mathrm{~nm}$ and a focus diameter of $5 \mu \mathrm{m}$. Figure S3a shows the X-ray diffraction (XRD) patterns for (atomic layer deposition) the $\mathrm{ALD}^{-\mathrm{HfO}_{2}}$ thin film $(50 \mathrm{~nm})$ on silicon. The XRD spectra were collected on a BRUKER-XRD system by using the $\mathrm{Cu} \mathrm{K} \alpha$ line (1.5402 $\mathrm{A}^{\mathrm{o}}$ of wavelength). Figure S3b shows the Raman spectra of the $\mathrm{SiO}_{2}(90 \mathrm{~nm}) / \mathrm{Si}$ heterostructure. The current-voltage (I-V) characteristics of the vertical heterostructured graphene-based n-Si/HfO 2 (50 nm)/DLG/p-AlGaN LED, n-Si/SiO 2 (90 nm)/DLG/p-AlGaN LED, and graphene free LEDs were measured by using a Keithley 2400 source meter in forward bias. The electroluminescence (EL) characterization was carried out by using an Ocean Optics QE Pro. 


\section{Results and Discussion}

Figure 1a shows the cross sectional HR-TEM image of the interface of n-Si/ $\mathrm{HfO}_{2}$ heterostructure. Figure $1 a_{1}$ shows the TEM image of the interface of the vertical heterostructured $n-S i / H f O=$ (cross-sectional view) at the $100 \mathrm{~nm}$ scale. Figure $1 \mathrm{a}_{2}, \mathrm{a}_{3}$ show the TEM images of the magnified cross-sectional view of the interface of the $n-\mathrm{Si} / \mathrm{HfO}_{2}$ heterostructure, from which a thickness of $54.5 \mathrm{~nm}$ for the $\mathrm{HfO}_{2}$ layer and a hetero-layered stacking of $\mathrm{Si}$ and $\mathrm{HfO}_{2}$ was read out respectively. The atomic layer deposition (ALD) growth of $\mathrm{HfO}_{2}$ on the $\mathrm{Si}$ accompanied the formation of $\mathrm{SiO}_{2}$ of a few nanometers thick as an interfacial layer between $\mathrm{Si}$ and $\mathrm{HfO}_{2}$ layers, as shown in Figure 1a 3 [27]. Figure $1 \mathrm{~b}$ shows the STEM-EDX elemental mapping of $\left(b_{1}\right) \mathrm{Si},\left(b_{2}\right) \mathrm{Hf},\left(b_{3}\right) \mathrm{Pt}$, and $\left(b_{4}\right) \mathrm{O}$ in the hetero-layered structure of $\mathrm{n}-\mathrm{Si} / \mathrm{HfO}_{2}$.

\section{TEM Characterization $\mathrm{n}-\mathrm{Si} / \mathrm{HfO}_{2}(50 \mathrm{~nm})$ heterostructure}

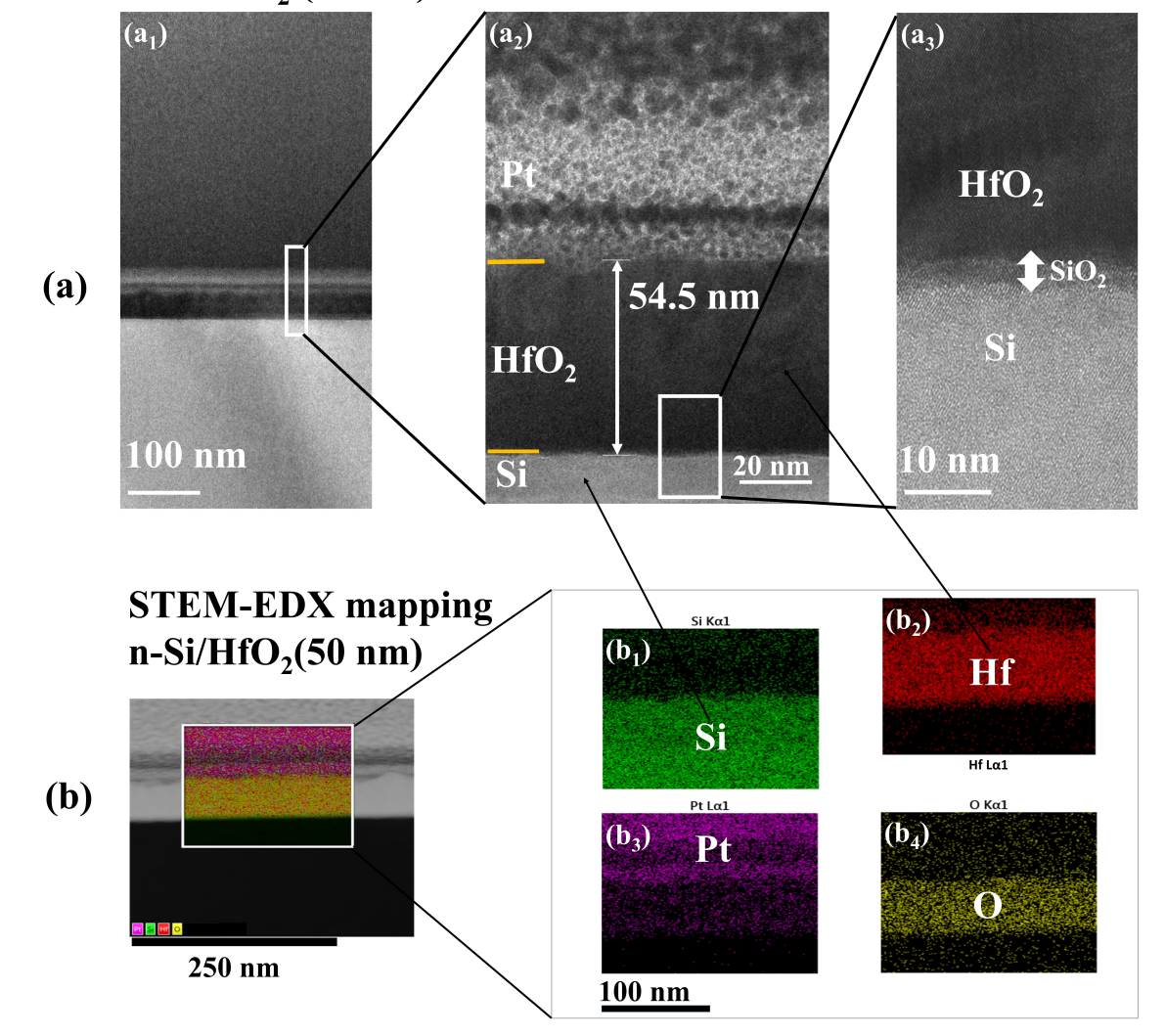

Figure 1. (a) Cross-sectional high-resolution Transmission Electron Microscope (HR-TEM) image of the interface of $\mathrm{n}-\mathrm{Si} / \mathrm{HfO}_{2}$ heterostructure. ( $\left.\mathbf{a}_{1}\right)$ Transmission Electron Microscope (TEM) image of cross-sectional view of the interface of $\mathrm{n}-\mathrm{Si} / \mathrm{HfO}_{2}$ with $100 \mathrm{~nm}$ scale. $\left(\mathbf{a}_{2}\right)$ and $\left(\mathbf{a}_{3}\right)$ TEM magnified view of the interface of n-Si/ $\mathrm{HfO}_{2}$, from which a thickness of $54.5 \mathrm{~nm}$ for the $\mathrm{HfO}_{2}$ layer, $\mathrm{SiO}_{2}$ interface layer, and a hetero-layered stacking of $\mathrm{Si}$ and $\mathrm{HfO}_{2}$ can be read out respectively. (b) STEM-EDX elemental mapping of $\left(\mathbf{b}_{1}\right) \mathrm{Si},\left(\mathbf{b}_{2}\right) \mathrm{Hf},\left(\mathbf{b}_{3}\right) \mathrm{Pt}$, and $\left(\mathbf{b}_{4}\right) \mathrm{O}$ in the hetero-layered structure of $\mathrm{n}-\mathrm{Si} / \mathrm{HfO}_{2}$.

Figure $2 \mathrm{a}-\mathrm{c}$ shows the schematic view of the graphene free $\mathrm{n}-\mathrm{Si} / \mathrm{HfO}_{2}(50 \mathrm{~nm}) / \mathrm{p}-\mathrm{AlGaN}$ LED, I-V characteristics of the LED, and EL chart of the LED. As shown in Figure 2a, in the $\mathrm{n}-\mathrm{Si} / \mathrm{HfO}_{2}(50 \mathrm{~nm}) / \mathrm{p}-\mathrm{AlGaN} \mathrm{LED}$, the hot electrons accumulate at the interface of the $\mathrm{n}-\mathrm{Si} / \mathrm{HfO}_{2}(50 \mathrm{~nm})$ heterostructure under forward bias [28]. With a relatively larger thickness of the dielectric layer $(50 \mathrm{~nm}, 90 \mathrm{~nm})$, the electron tunneling mechanism will be marginal and the electron-impact ionization mechanism would be the prime contributor for the electron transfer through the dielectric layer. 
(a)

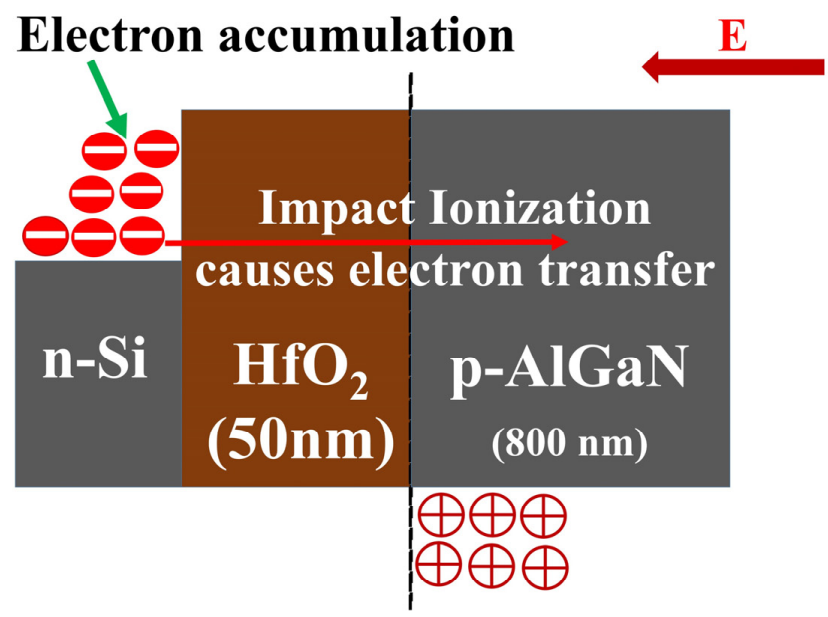

(b)

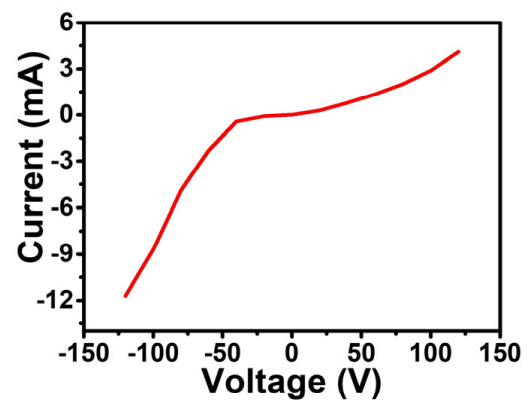

(c)

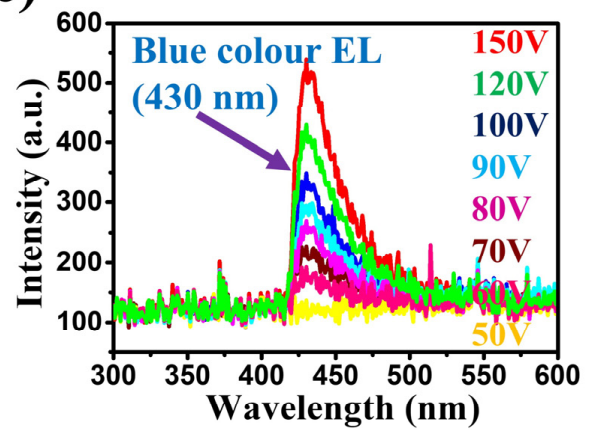

Figure 2. (a) Pictorial view of the graphene free $n-S i / \mathrm{HfO}_{2} / \mathrm{p}-\mathrm{AlGaN}$ LED. (b) Current-Voltage (I-V) characteristic curve of the LED. (c) Electroluminescence (EL) of the LED at forward bias applied voltages.

Electrically induced high energy hot electrons can strongly interact with the lattice of the dielectric layer, causing the emission of more electrons and these electrons can transfer to the p-AlGaN, but the Coulomb scattering of these charges at the $\mathrm{p}-\mathrm{AlGaN}$ leads to electron-lattice interactions resulted in a predominantly unproductive recombination (heat as major outcome), hence merely a detectable blue color very low intensity EL (wavelength $430 \mathrm{~nm}$ ) was observed from the LED as shown in Figure 2c. Figure S4a shows the I-V curve of the graphene-free n-Si/ $\mathrm{Al}_{2} \mathrm{O}_{3}(10 \mathrm{~nm}) / \mathrm{p}-\mathrm{AlGaN}$ LED with a $10 \mathrm{~nm}$ thickness of the dielectric layer, and at forward bias a low intensity EL with $430 \mathrm{~nm}$ (blue light) along with a stumpy peak of defect based EL was observed from the LED, as shown in Figure S4b.

Figure $3 \mathrm{a}-\mathrm{c}$ shows the device structure of $\mathrm{n}-\mathrm{Si} / \mathrm{HfO}_{2}(50 \mathrm{~nm}) / \mathrm{DLG} / \mathrm{p}-\mathrm{AlGaN}$ LED, I-V characteristics of the LED, and EL of the LED in forward bias, respectively. Figure $4 a, b$ shows the energy band profile of the $\mathrm{n}-\mathrm{Si} / \mathrm{HfO}_{2}(50 \mathrm{~nm}) / \mathrm{DLG} / \mathrm{p}-\mathrm{AlGaN}$ LED under zero bias and at forward bias, respectively. In the $\mathrm{n}-\mathrm{Si} / \mathrm{HfO}_{2}(50 \mathrm{~nm}) / \mathrm{DLG} / \mathrm{p}-\mathrm{AlGaN}$ LED, at zero bias, DLG displayed a slight p-type nature, as shown in Figure 4c. The unavoidable presence of metal ions, the residues of Polymethyl methacrylate (PMMA) on the graphene, and the transfer of graphene onto the $\mathrm{AlGaN}$ all together led to the slight p-type doped DLG $[29,30]$. The transfer of DLG onto the p-AlGaN resulted in the formation of an energy barrier $\left(E_{B}\right)$ for the electron transfer from graphene to the p-AlGaN at the interface of DLG/p-AlGaN and the slight p-type behavior of DLG and intrinsic polarization effects of $\mathrm{p}-\mathrm{AlGaN}$ caused the Schottky effects, and ascended the energy barrier $\mathrm{E}_{\mathrm{B}}$ between DLG and the p-AlGaN, as shown in Figure 4c [31-34]. 
(a)

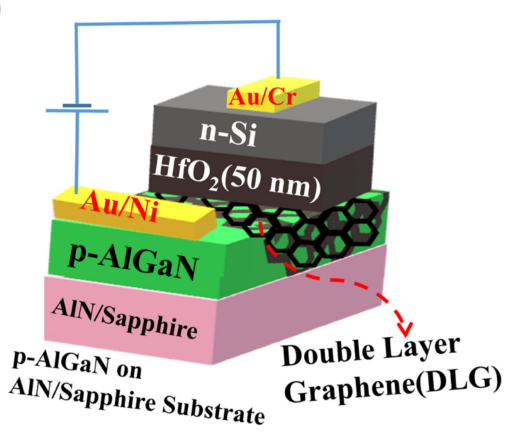

(b)

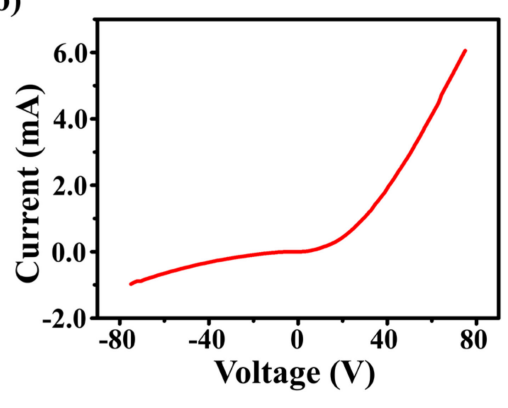

(c)

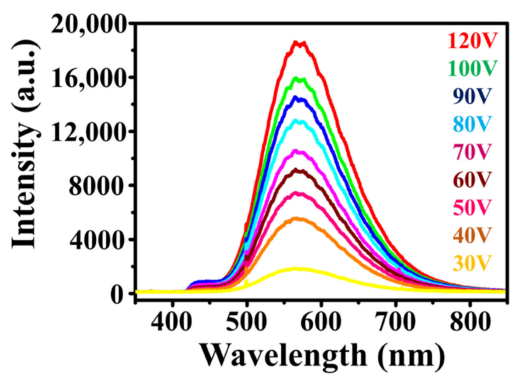

Figure 3. (a) Structure of $n-\mathrm{Si} / \mathrm{HfO}_{2} / \mathrm{DLG} / \mathrm{p}-\mathrm{AlGaN}$ LED. (b) Current-Voltage (I-V) characteristics of the LED. (c) Electroluminescence (EL) of the LED at applied forward bias voltages. Defects based broadband yellow color with peak center at $580 \mathrm{~nm}$.

(a)

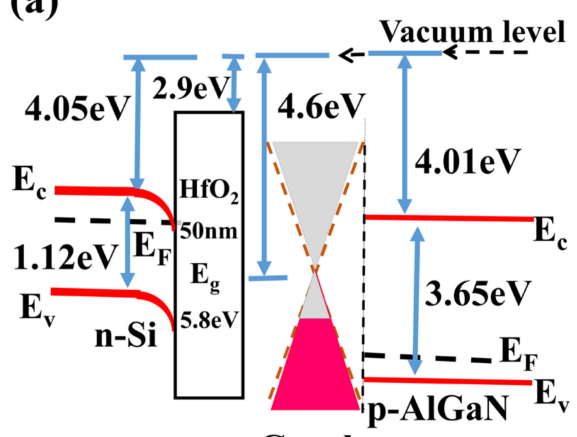

Graphene

Thermal equilibrium

(c)

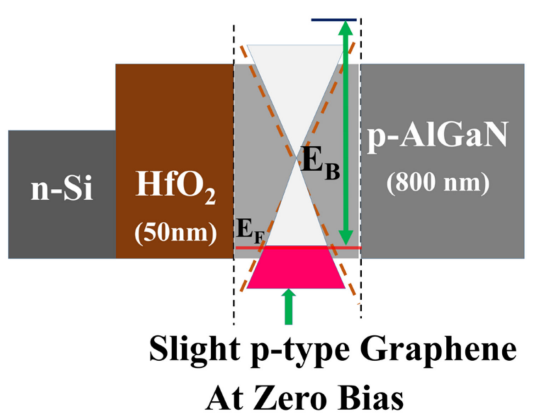

(b)

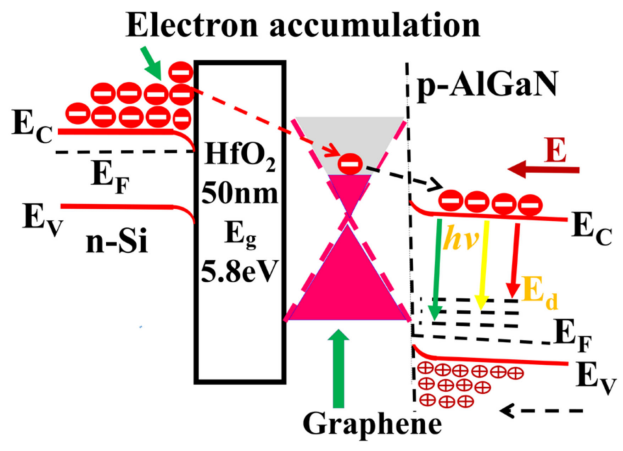

Forward Bias

(d)

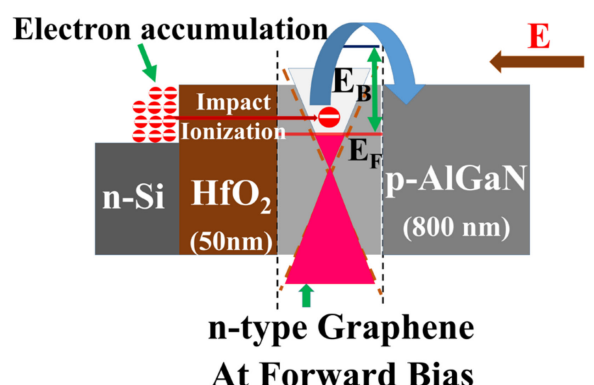

Figure 4. (a) Energy band profile of $n-\mathrm{Si} / \mathrm{HfO}_{2} / \mathrm{DLG} / \mathrm{p}-\mathrm{AlGaN}$ vertical semiconductor heterostructure under zero bias condition. (b) The illumination mechanism of the LED at forward bias voltages. (c) Pictorial view of the electronic band profile of graphene in the LED at zero bias. (d) Pictorial view of the band profile of graphene in the LED at forward bias. Electric field induced hot electron accumulation at the graphene led to the n-type doped graphene and rise in Fermi level of the graphene. 
At applied forward voltages, the electric field induced hot electrons accumulated at the interface of the $\mathrm{n}-\mathrm{Si} / \mathrm{HfO}_{2}$ heterostructure can cross the thick dielectric barrier $(50 \mathrm{~nm})$ by the electron-impact ionization mechanism [35-38] and are injected into the graphene. The superior electronic behavior of graphene [39-43] (like strong electron-electron interactions, high electrical conductivity along the plane, high charge carrier mobility, and weak charge carrier scattering, etc.) enables the accumulation of hot electrons at the graphene, which may amplify the numbers of electrons through multiplication exciton effect.

The accumulation of electrically induced hot electrons at the graphene [44,45] (resistant to the extrinsic scattering of electrons) led to the n-type doped graphene or a rise in the Fermi level of graphene, which reduces the energy barrier $\left(\mathrm{E}_{\mathrm{B}}\right)$ between the graphene and $\mathrm{p}-\mathrm{AlGaN}$, resulting in the significant electron transport from graphene to the p-AlGaN, as shown in Figure 4d [46]. Hence, the excess of negative charge or numerous hot electrons available at the graphene can be effectively transferred into the p-AlGaN, as shown in Figure 4b,d [47-49], which leads to the radiative recombination of holes with the readily available hot electrons at the p-AlGaN, which resulted in a defect based strong EL or high-intensity yellow color with the center of the peak at $580 \mathrm{~nm}$, as shown in Figure 3c, where a further increase in the forward applied voltage increased the intensity of the yellow color illumination. Experimentally no significant illumination or very low intensity EL was observed without the presence of graphene from the LED, as shown in Figure 2c and Figure S4. The accumulation of hot electrons at the graphene is the key factor for the illumination of intense EL from the LED.

Figure $5 \mathrm{a}-\mathrm{c}$ shows the graphene free $\mathrm{n}-\mathrm{Si} / \mathrm{SiO} 2(90 \mathrm{~nm}) / \mathrm{p}-\mathrm{AlGaN}$ LED, I-V curve of the LED, and the EL from the LED at forward bias applied voltages, respectively. There was no detectable light emission from the graphene free $\mathrm{n}-\mathrm{Si} / \mathrm{SiO} 2(90 \mathrm{~nm}) / \mathrm{p}$-AlGaN device at moderate applied voltages (below $70 \mathrm{~V}$ ), but at very high applied voltages (about $100 \mathrm{~V}$ ), a blue colored very weak EL (430 nm) was observed (Figure 5c). At forward applied voltages, the illumination mechanism in the graphene free silica dielectric based LED was similar to the graphene free $\mathrm{n}-\mathrm{Si} / \mathrm{HfO} 2(50 \mathrm{~nm}) / \mathrm{p}-\mathrm{AlGaN}$ LED. The electrically induced hot electrons accumulated at the interface of $\mathrm{n}-\mathrm{Si} / \mathrm{SiO} 2$ can cross the thick dielectric barrier via electron-impact ionization, but due to the scattering of charge carriers and electron-lattice interactions at the p-AlGaN, unproductive recombination would predominate, which leads to the very low intensity EL (blue color).

Figure $5 \mathrm{~d}$ and Figure 55 both show the schematic illustration of the n-Si/SiO $2(90 \mathrm{~nm}) / \mathrm{DLG} / \mathrm{p}-\mathrm{AlGaN}$ LED, while Figure S6a,b shows the electronic band alignment at zero bias and the illumination mechanism of LED at forward bias, respectively. Figure 5e shows the I-V characteristics of the LED. We made an enthusiastic study regarding the influence of the thickness of the dielectric on the EL from the LED. The light emission mechanism of the n-Si/SiO $2(90 \mathrm{~nm}) / \mathrm{DLG} / \mathrm{p}-\mathrm{AlGaN}$ LED was similar to that of the $n-\mathrm{Si} / \mathrm{HfO}_{2}(50 \mathrm{~nm}) / \mathrm{DLG} / \mathrm{p}-\mathrm{AlGaN}$ LED. In the n-Si/SiO${ }_{2}(90 \mathrm{~nm}) / \mathrm{DLG} / \mathrm{p}-\mathrm{AlGaN}$ LED, under forward voltages, the electron-impact ionization mechanism enables the transfer of hot electrons through the thick dielectric layer, and the electrically induced hot electron accumulation at the graphene caused the rise in the Fermi level of graphene and reduction in the $\mathrm{E}_{\mathrm{B}}$, which led to the efficient electron transport from graphene to the $\mathrm{p}-\mathrm{AlGaN}$. The readily available hot electrons at the p-AlGaN recombined with the holes, resulting in a defect based broadband high-intensity yellow color emission, as shown in Figure 5f. In a comparative EL study between $\mathrm{HfO}_{2}(50 \mathrm{~nm})$ and $\mathrm{SiO}_{2}$ $(90 \mathrm{~nm})$ dielectric layer based graphene LEDs, the moderately lower EL from the silica dielectric based graphene LED, with no drastic EL variations infers the vital role of the electron-impact ionization mechanism. The comparative EL study between the graphene free and graphene based LEDs at the different thickness of the dielectric layer revealed that even though the impact ionization was a necessary step for electron transfer through the dielectric layer, it was not a crucial influential factor for the intense EL from the LED at the respective thickness of the dielectric layer, and it highlights the graphene as a key component for the illumination mechanism of the LED.

Graphene (G), as an interfacial layer between two semiconductors (S), acts as an electric field induced hot electron accumulation layer, and displays an n-type nature, favoring the efficient electron 
transfer from graphene to the semiconductor, which may have significant applications in S-G-S (S-M-S) type hot electron based electronic and optoelectronic devices. Van der Waals integration makes possible a wide variety of S-G-S combinations.

(a)

(c)
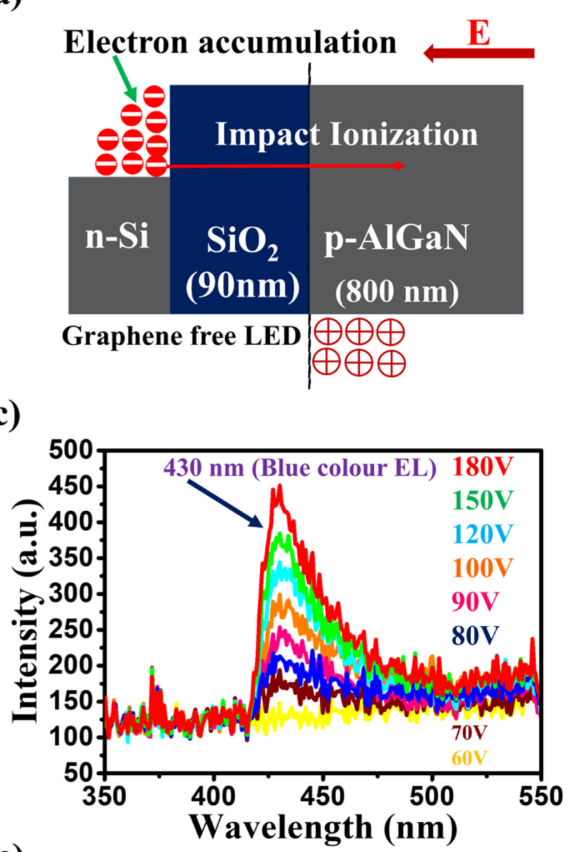

(e)

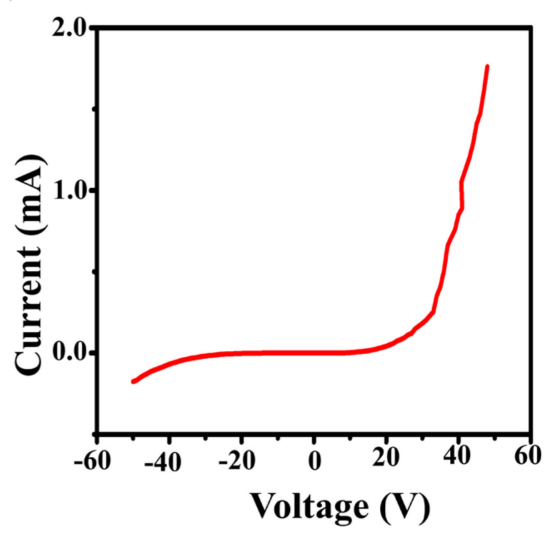

(b)

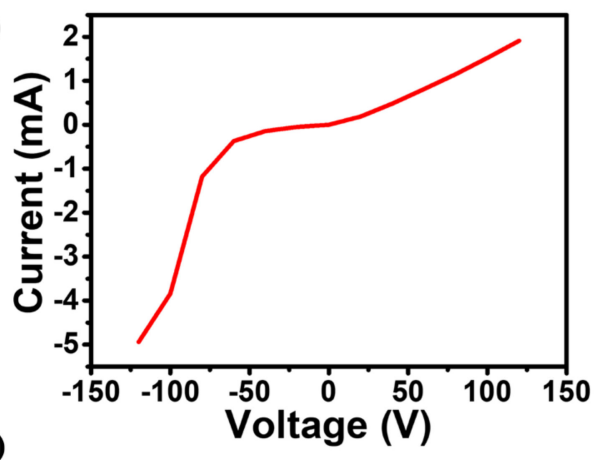

(d)

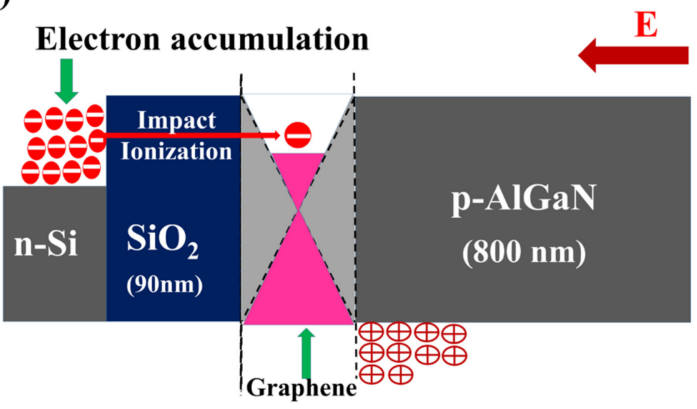

(f)

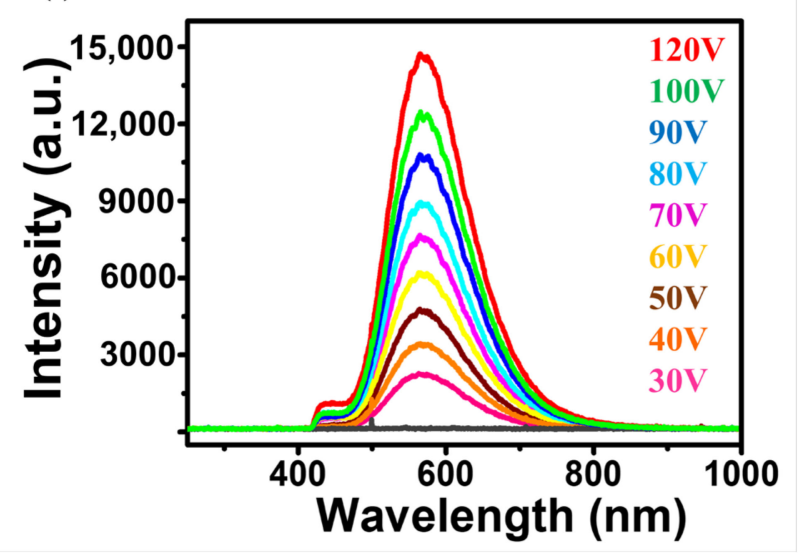

Figure 5. (a) Schematic representation of the structure of graphene free $n-S i / S i O_{2} / p-A l G a N ~ L E D$. (b) Current-Voltage (I-V) curve of the graphene free LED. (c) Electroluminescence (EL) of the graphene free LED at forward bias applied voltages. (d) Pictorial view of the graphene based $\mathrm{Si} / \mathrm{SiO}_{2} / \mathrm{DLG} / \mathrm{AlGaN}$ LED. (e) I-V curve of the graphene based LED. (f) EL from the graphene based LED in forward bias. The illumination from the graphene based LED was a defect based broadband yellow color with a wavelength maxima $\left(\lambda_{\max }\right)$ at $580 \mathrm{~nm}$.

\section{Conclusions}

In conclusion, we fabricated the $\mathrm{n}-\mathrm{Si} / \mathrm{HfO}_{2}(50 \mathrm{~nm}) / \mathrm{DLG} / \mathrm{p}-\mathrm{AlGaN}$ LED and n-Si/SiO $2(90 \mathrm{~nm}) /$ DLG/p-AlGaN LED by using the van der Waals integration method. In forward applied bias voltages, the silicon/dielectric layer $\left(\mathrm{HfO}_{2}, \mathrm{SiO}_{2}\right)$ heterostructure accumulates numerous hot electrons at the interface of the Si/dielectric layer, and these electrically induced hot electrons are capable of crossing the thick dielectric barrier via electron-impact ionization mechanism and can be injected into the graphene. The superior electronic behavior of graphene alike strong electron-electron interactions, high conductivity along the plane, etc., leads to the accumulation of hot electrons at the graphene, 
and CM effect in graphene multiply the numbers of electrons and eventually transfers to p-AlGaN and contribute to the emission. The accumulation of hot electrons at the graphene results in a rise in the Fermi level of graphene, which also reduces the energy barrier $E_{B}$ for electron transfer from graphene to the AlGaN. Hence, at applied forward voltages, the excess hot electrons injected into the graphene can effectively cause electron multiplication and efficiently transfer into p-AlGaN, herein holes recombine with these hot electrons at a significant rate, causing the broadband yellow color EL with a center peak at $580 \mathrm{~nm}$.

Experimentally, the graphene free n-Si/HfO $2(50 \mathrm{~nm}) / \mathrm{p}-\mathrm{AlGaN} \mathrm{LED}$ and n-Si/SiO $2(90 \mathrm{~nm}) / \mathrm{p}-\mathrm{AlGaN}$ LED showed a blue color, merely detectable, very low intensity EL (430 nm), even at very high applied forward voltages $(120 \mathrm{~V})$. The graphene based $\mathrm{n}-\mathrm{Si} /$ dielectric layer $\left(\mathrm{HfO}_{2}-50 \mathrm{~nm}, \mathrm{SiO}_{2}-90 \mathrm{~nm}\right) /$ DLG/p-AlGaN LED structures both showed high EL at applied forward voltages. Comparatively, no extreme change in the intensities of EL from the graphene based LEDs was observed, which specifies the significant role of the electron-impact ionization mechanism for electron transfer through the thick dielectric layer. The DLG is the key component, acts as a hot electron accumulator, and plays a vital role in the illumination of the LED. The $\mathrm{Si} /$ dielectric layer $\left(\mathrm{HfO}_{2}, \mathrm{SiO}_{2}\right.$ with optimized thickness) heterostructure is necessary for a strong, high EL of the LED. The present Si/dielectric layer/graphene/AlGaN based LED demonstrates a unique device design and the importance of graphene for a better performance of silicon-based LEDs, which may find significant applications in the field of silicon compatible optoelectronics.

Supplementary Materials: The following are available online at http://www.mdpi.com/2079-4991/10/12/2568/s1, Figure S1: CVD growth of graphene, Figure S2: The Raman spectra of graphene, Figure S3: XRD pattern of the $50 \mathrm{~nm} \mathrm{HfO}_{2}$ on n-type $\mathrm{Si}$, and Raman spectra of n-type $\mathrm{Si} / \mathrm{SiO}_{2}$ heterostructure respectively, Figure S4: Graphene free $\mathrm{Si} / \mathrm{Al}_{2} \mathrm{O}_{3}(10 \mathrm{~nm}) / \mathrm{AlGaN}$ LED, Figure S5: Pictorial representation of the $\mathrm{Si}_{/} / \mathrm{SiO}_{2}(90 \mathrm{~nm}) / \mathrm{DLG} / \mathrm{AlGaN}$ LED, Figure S6: Illumination mechanism of the Si/dielectric layer $\left(\mathrm{SiO}_{2}\right) / \mathrm{DLG} / \mathrm{AlGaN} \mathrm{LED.}$

Author Contributions: Conceptualization, N.K.M.; methodology, N.K.M.; validation, N.K.M., S.L.; formal analysis, N.K.M.; investigation, N.K.M.; resources, N.K.M., S.L., Y.L., X.Y.; data curation, N.K.M.; writing-original draft preparation, N.K.M., C.L., S.L.; writing-review and editing, N.K.M., S.L., C.L.; visualization, N.K.M., S.L.; supervision, S.L.; project administration, S.L.; funding acquisition, S.L. All authors have read and agreed to the published version of the manuscript.

Funding: This research was funded by the National Natural Science Foundation of China (grant numbers 51202216, 51502264, 61774135) and the Special Foundation of Young Professor of Zhejiang University (grant number 2013QNA5007).

Conflicts of Interest: The authors declare no conflict of interest.

\section{References}

1. Nakamura, S.; Harada, Y.; Senoh, M. Novel metalorganic chemical vapor deposition system for GaN growth. Appl. Phys. Lett. 1991, 58, 2021-2023. [CrossRef]

2. Nakamura, S.; Iwasa, N.; Senoh, M.; Mukai, T. Hole Compensation Mechanism of P-Type GaN Films. Jpn. J. Appl. Phys. 1992, 31, 1258-1266. [CrossRef]

3. Akasaki, I.; Amano, H. Crystal growth and conductivity control of group III nitride semiconductors and their application to short wavelength light emitters. Jpn. J. Appl. Phys. 1997, 36, 5393-5408. [CrossRef]

4. Nakamura, S.; Mukai, T.; Senoh, M.; Iwasa, N. Thermal Annealing Effects on P-Type Mg-Doped GaN Films. Jpn. J. Appl. Phys. 1992, 31, L139-L142. [CrossRef]

5. Ball, P. Let there be light. Nature 2001, 409, 974-976. [CrossRef] [PubMed]

6. Leong, D.; Harry, M.; Reeson, K.J.; Homewood, K.P. A silicon/iron disilicide light-emitting diode operating at a wavelength of $1.5 \mathrm{~mm}$. Nature 1997, 387, 686-688. [CrossRef]

7. Ng, W.L.; Lourenç, M.A.; Gwilliam, R.M.; Ledain, S.; Shao, G.; Homewood, K.P. An efficient room-temperature silicon-based light-emitting diode. Nature 2001, 410, 192-194. [CrossRef]

8. Hirschman, K.D.; Tybekov, L.; Duttagupta, S.P.; Fauchet, P.M. Silicon-based visible light-emitting devices integrated into microelectronic circuits. Nature 1996, 384, 338-341. [CrossRef]

9. Castagna, M.E.; Coffa, S.; Monaco, M.; Muscara, A.; Caristia, L.; Lorenti, S.; Messina, A. High efficiency light emitting devices in silicon. Mater. Sci. Eng. B 2003, 105, 83-90. [CrossRef] 
10. Michael, K.; Jens, R. III-Nitride Ultraviolet Emitters, 1st ed.; Springer: Cham, Switzerland, 2016.

11. Philip, M.R.; Choudhary, D.D.; Djavid, M.; Le, K.Q.; Piao, J.; Nguye, H.P.T. High efficiency green/yellow and red InGaN/AlGaN nanowire light-emitting diodes grown by molecular beam epitaxy. J. Sci. Adv. Mater. Devices 2017, 2, 150-155. [CrossRef]

12. Feng, S.; Dong, B.; Lu, Y.; Yin, L.; Wei, B.; Wang, J.; Lin, S. Graphene/p-AlGaN/p-GaN electron tunnelling light emitting diodes with high external quantum efficiency. Nano Energy 2019, 60, 836-840. [CrossRef]

13. Novoselov, K.S.; Jiang, D.; Schedin, F.; Booth, T.J.; Khotkevich, V.V.; Morozov, S.V.; Geim, A.K. Two-dimensional atomic crystals. Proc. Natl. Acad. Sci. USA 2005, 102, 10451-10453. [CrossRef] [PubMed]

14. Novoselov, K.S.; Geim, A.K.; Morozov, S.V.; Jiang, D.; Zhang, Y.; Dubonos, S.V.; Grigorieva, I.V.; Firsov, A.A. Electric Field Effect in Atomically Thin Carbon Films. Science 2004, 306, 666-669. [CrossRef] [PubMed]

15. Geim, A.K.; Grigorieva, I.V. Van der Waals heterostructures. Nature 2013, 499, 419-425. [CrossRef]

16. Wang, L.; Liu, W.; Zhang, Y.; Zhang, Z.-H.; Tan, S.T.; Wang, G.; Sun, X.; Zhu, H.; Demir, H.V. Graphene-Based Transparent Conductive Electrodes for GaN-Based Light Emitting Diodes: Challenges and Countermeasures. Nano Energy 2015, 12, 419-436. [CrossRef]

17. Khrapach, I.; Withers, F.; Bointon, H.T.; Polyushkin, D.K.; Barnes, W.L.; Russo, S.; Craciun, M.F. Novel Highly Conductive and Transparent Graphene-Based Conductors. Adv. Mater. 2012, 24, 2844-2849. [CrossRef]

18. Hoiaas, I.M.; Mulyo, A.L.; Vullum, P.E.; Kim, D.-C.; Ahtapodov, L.; Fimland, B.-O.; Kishino, K.; Weman, H. GaN/AlGaN Nanocolumn Ultraviolet Light-Emitting Diode Using Double-Layer Graphene as Substrate and Transparent Electrode. Nano Lett. 2019, 19, 1649-1658. [CrossRef]

19. Cao, Y.; Fatemi, V.; Demir, A.; Fang, S.; Tomarken, S.L.; Luo, J.Y.; Javier, D.; Watanabe, K.; Taniguchi, T.; Kaxiras, E.; et al. Correlated insulator behaviour at half-filling in magic-angle graphene superlattices. Nature 2018, 556, 26154. [CrossRef]

20. Winzer, T.; Malić, E. Impact of Auger processes on carrier dynamics in graphene. Phys. Rev. B 2012, 85, 241404. [CrossRef]

21. Gabor, N.M. Impact Excitation and Electron-Hole Multiplication in Graphene and Carbon Nanotubes. Acc. Chem. Res. 2013, 46, 1348-1357. [CrossRef]

22. Park, H.; Fang, A.W.; Kodama, S.; Bowers, J.E. Hybrid silicon evanescent laser fabricated with a silicon waveguide and III-V offset quantum wells. Opt. Express. 2005, 13, 9460. [CrossRef] [PubMed]

23. Philip, M.R.; Choudhary, D.D.; Djavid, M.; Bhuyian, M.N.; Piao, J.; Pham, T.T.; Misra, D.; Nguyen, H.P.T. Controlling color emission of InGaN/AlGaN nanowire light-emitting diodes grown by molecular beam epitaxy. J. Vac. Sci. Technol. B 2017, 35, 02B108-1-02B108-5. [CrossRef]

24. Motohisa, J.; Kameda, H.; Sasaki, M.; Tomioka, K. Characterization of nanowire light-emitting diodes grown by selective-area metal-organic vapor-phase epitaxy. Nanotechnology 2019, 30, 134002. [CrossRef] [PubMed]

25. Liu, Y.; Huang, Y.; Duan, X. Van der Waals integration before and beyond two-dimensional materials. Nature 2019, 567, 323-333. [CrossRef]

26. Liu, Y.; Wang, P.; Wang, Y.; Lin, Z.; Liu, H.; Huang, J.; Huang, Y.; Duan, X. Van der Waals Integrated Devices Based on Nanomembranes of 3D Materials. Nano Lett. 2020, 20, 1410-1416. [CrossRef]

27. McNeill, D.W.; Bhattacharya, S.; Wadsworth, H.; Ruddell, F.H.; Mitchell, S.J.N.; Armstrong, B.M.; Gamble, H.S. Atomic layer deposition of hafnium oxide dielectrics on silicon and germanium substrates. J. Mater. Sci. Mater. Electron. 2008, 19, 119-123. [CrossRef]

28. Balkan, N.; Teke, A.; Gupta, R.; Straw, A.; Wolter, J.H.; Vleuten, W.v.d. Tunable wavelength hot electron light emitter. Appl. Phys. Lett. 1995, 67, 935-937. [CrossRef]

29. Lee, H.; Paeng, K.; Kim, I.S. A review of doping modulation in graphene. Synth. Met. 2018, $244,36-47$. [CrossRef]

30. Kwon, K.C.; Kim, S.Y. Extended thermal stability in metal-chloride doped graphene using graphene overlayers. Chem. Eng. Sci. 2014, 244, 355-363. [CrossRef]

31. Dub, M.; Sai, P.; Przewłoka, A.; Krajewska, A.; Sakowicz, M.; Prystawko, P.; Kacperski, J.; Pasternak, I.; But, D.; Knap, W.; et al. Graphene as a Schottky Barrier Contact to AlGaN/GaN Heterostructures. Materials 2020, 13, 4140. [CrossRef]

32. Park, P.S.; Reddy, K.M.; Nath, D.N.; Padture, N.P.; Rajan, S. Electrical Properties of Graphene/AlGaN/GaN Heterostructures. Mater. Sci. Forum. 2015, 821, 986-989. 
33. Pandit, B.; Seo, T.H.; Ryu, B.D.; Cho, J. Current transport mechanism in graphene/AlGaN/GaN heterostructures with various Al mole fractions. AIP Adv. 2016, 6, 065007. [CrossRef]

34. Liao, L.; Bai, J.; Cheng, R.; Lin, Y.-C.; Jiang, S.; Qu, Y.; Huang, Y.; Duan, X. Sub-100 nm Channel Length Graphene Transistors. Nano Lett. 2010, 10, 3952-3956. [CrossRef] [PubMed]

35. Dervos, C.; Bourkas, P.D.; Kagarakis, C.A. Charge transport trough a "metal-thick insulator metal" structure during impulse voltage excitation. J. Electrostat. 1991, 26, 121-132. [CrossRef]

36. Kanitz, S. Charge transport in thick $\mathrm{SiO}_{2}$-based dielectric layers. Solid State Electron. 1997, 41, $1895-1902$. [CrossRef]

37. Nakamura, K.; Takahashi, T. An Observation of Breakdown Characteristics on Thick Silicon Oxide. In Proceedings of the 1995 ISPSD, Yokohama, Japan, 23-25 May 1995; ISBN 0-7803-2618-0.

38. Hwang, W.; Kim, Y.K.; Rudd, M.E. New model for electron-impact ionization cross sections of molecules. J. Chem. Phys. 1996, 104, 2956-2966. [CrossRef]

39. Jobst, J.; Waldmann, D.; Gornyi, I.V.; Mirlin, A.D.; Weber, H.B. Electron-Electron Interaction in the Magnetoresistance of Graphene. PRL 2012, 108, 106601. [CrossRef]

40. Bolotin, K.I.; Ghahari, F.; Shulman, M.D.; Stormer, H.L.; Kim, P. Observation of the fractional quantum Hall effect in graphene. Nature 2009, 462, 196-199. [CrossRef]

41. Du, X.; Skachko, I.; Duerr, F.; Luican, A.; Andrei, E.Y. Fractional quantum Hall effect and insulating phase of Dirac electrons in graphene. Nature 2009, 462, 192-195. [CrossRef]

42. Morozov, S.V.; Novoselov, K.S.; Katsnelson, M.I.; Schedin, F.; Elias, D.C.; Jaszczak, J.A.; Geim, A.K. Giant Intrinsic Carrier Mobilities in Graphene and Its Bilayer. PRL 2008, 100, 016602. [CrossRef] [PubMed]

43. Bolotin, K.I. Electronic transport in graphene: Towards high mobility. In Graphene: Properties, Preparation, Characterisation and Devices (Woodhead Publishing Series in Electronic and Optical Materials), 1st ed.; Viera, S., Kaiser, A.B., Eds.; Woodhead Publishing Limited: Cambridge, UK, 2014; pp. 199-227. ISBN 13-978-0857095084.

44. Kim, Y.D.; Kim, H.; Cho, Y.; Ryoo, I.H.; Park, Y.D.; Kim, P.; Kim, Y.S.; Lee, S.; Li, Y.; Park, S.-N.; et al. Bright visible light emission from graphene. Nat. Nanotechnol 2015, 10, 676-681. [CrossRef] [PubMed]

45. Gabor, N.M.; Song, J.C.W.; Ma, Q.; Nair, N.L.; Taychatanapat, T.; Watanabe, K.; Taniguchi, T.; Levitov, L.S.; Herrero, P.J. Hot Carrier-Assisted Intrinsic Photoresponse in Graphene. Science 2011, 334, 648-652. [CrossRef] [PubMed]

46. Yu, Y.-J.; Zhao, Y.; Ryu, S.; Brus, L.E.; Kim, K.S.; Kim, P. Tuning the Graphene Work Function by Electric Field Effect. Nano Lett. 2009, 9, 3430-3434. [CrossRef]

47. Chang, C.-W.; Tan, W.-C.; Lu, M.-L.; Pan, T.-C.; Yang, Y.-J.; Chen, Y.-F. Graphene/SiO $2 /$ p-GaN Diodes: An Advanced Economical Alternative for Electrically Tunable Light Emitters. Adv. Funct. Mater. 2013, 23, 4043-4048. [CrossRef]

48. Yang, H.; Heo, J.; Park, S.; Song, H.J.; Seo, D.H.; Byun, K.-E.; Kim, P.; Yoo, I.K.; Chung, H.-J.; Kim, K. Graphene Barristor, a Triode Device with a Gate-Controlled Schottky Barrier. Science 2012, 336, 1140. [CrossRef]

49. Sun, Y.; Sun, M.; Xie, D. Graphene Electronic Devices. Graphene: Fabrication, Characterizations, Properties and Applications, 1st ed.; Hongwei, Z., Zhiping, X., Dan, X., Ying, F., Eds.; Academic Press: Waltham, MA, USA, 2018; pp. 103-155.

Publisher's Note: MDPI stays neutral with regard to jurisdictional claims in published maps and institutional affiliations.

(C) 2020 by the authors. Licensee MDPI, Basel, Switzerland. This article is an open access article distributed under the terms and conditions of the Creative Commons Attribution (CC BY) license (http://creativecommons.org/licenses/by/4.0/). 